\title{
Study of the Temperature and Acoustic Emission Characteristics of the Concrete Hardening Process with Different Ways of Curing
}

\author{
L. Topoláŕ \& L. Pazdera* \\ Department of Physics, Faculty of Civil Engineering, Brno University of Technology, Czech \\ *Corresponding author: Pazdera.L@fce.vutbr.cz
}

V. Bílek

ZPSV a.s., Czech

J. Smutný

Department of Railway Constructions and Structures, Faculty of Civil Engineering, Brno University of Technology, Czech Republic

\begin{abstract}
Concrete is a basic building material. This article describes its properties. Microcracks result from volume changes in concrete. The intensity of temperature development and the way concrete is being cured have a significant influence on the emergence of microcracks. Indeed, the quantification of microcracks isn't simple. Using acoustic emissions it is possible to observe the evolution of scratches in hardening concrete - how many of them evolve and how the intensity of their emergence changes depending on different regimes of curing or different types of concrete (different cement batches, various additives and admixtures, etc.).
\end{abstract}

KEY WORDS: Acoustic Emission Method, concrete, hardening, microcrack, Non Destructive Testing, High Performance Concrete

\section{INTRODUCTION}

High Performance Concrete (HPC) can be defined as a concrete made with appropriate materials (super-plasticizer, retarder, fly ash, blast furnace slag and silica fume) combined according to a selected mix design and properly mixed, transported, placed, consolidated, and cured to provide excellent performance in some specific areas of the properties of concrete, such as high compressive strength and high durability (high density, low permeability, and good resistance to certain forms of attack). An important part of concrete quality is concrete setting. However, there are some new problems. (Bilek et. all., 2001; Morin R. et all,2002)

The hydration of cement is an exothermic process. During hydration concrete obtains strength and other mechanical properties but it also shrinks. While for usual concrete drying shrinkage is the main component of total shrinkage, in the case of HPC the role of autogenous 
shrinkage increases. The shrinkage affects the creation of micro-cracks which lower the durability of the concrete. The course of total volume exchange is affected by temperature development, see Figure 1.

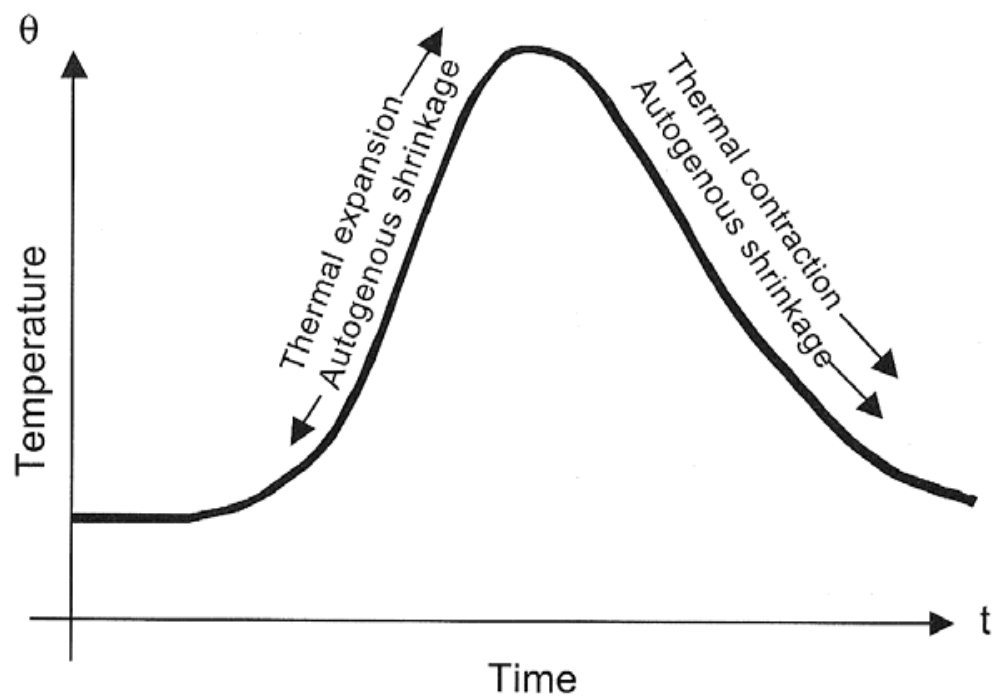

Figure 1: Why is important to know the heat development course of concrete. (Aitcin, 1998)

On the basis of the temperature course it is possible to select the best way of concrete curing to avoid micro-cracking. During the early stages of curing the autogenously shrinkage decreases thermal expansion. After the peak temperature is reached, however, autogenously shrinkage and thermal contraction act together in reducing volume and thereby creating micro-cracks. (Aitcin, 1998)

Acoustic Emission is the class of phenomena whereby an elastic wave, in the range of ultrasound (usually between $20 \mathrm{KHz}$ and $1 \mathrm{MHz}$ ), is generated by the rapid release of energy from the source within a material. The elastic wave propagates through the solid to the surface, where it can be recorded by one or more sensors (see Figure 2). The sensor is a transducer that converts the mechanical waves into an electrical signal. (Pollock A.A., 1988)

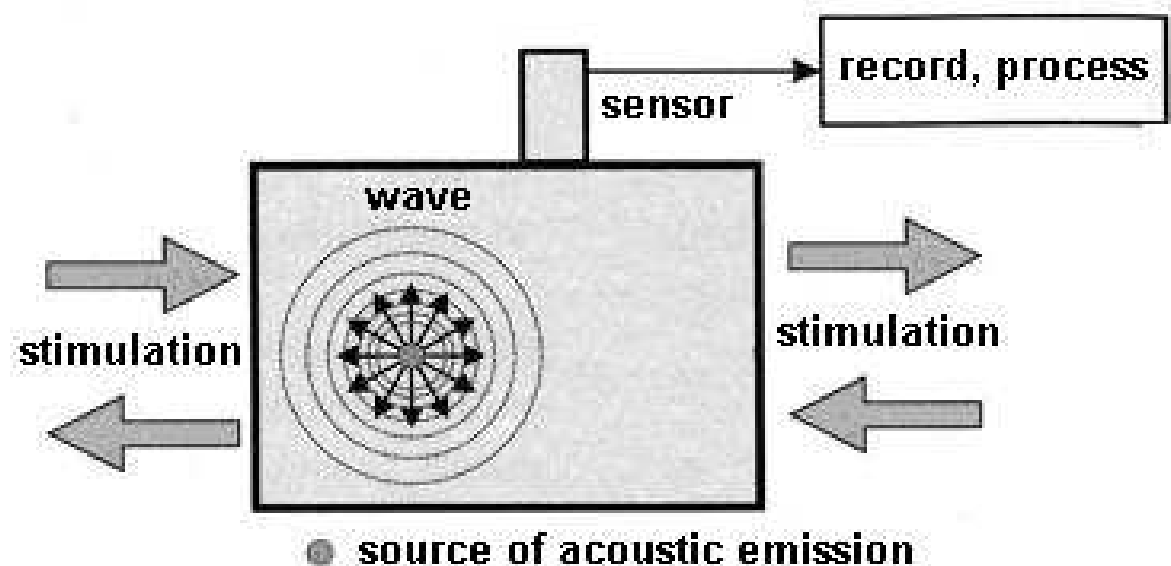

Figure 2: Rise and propagation undulation at a matter's acoustic emission (Mazal et all, 2005) 


\section{EXPERIMENTAL SETUP}

Temperature measurement during concrete setting was made with thermal resistors NTC K164NK022. Two sensors detected room temperature and three sensors were included within the concrete specimen. Two specimens were tested simultaneously. A block diagram of the experimental set-up is shown in Figure 3 and its photo is in Figure 4.

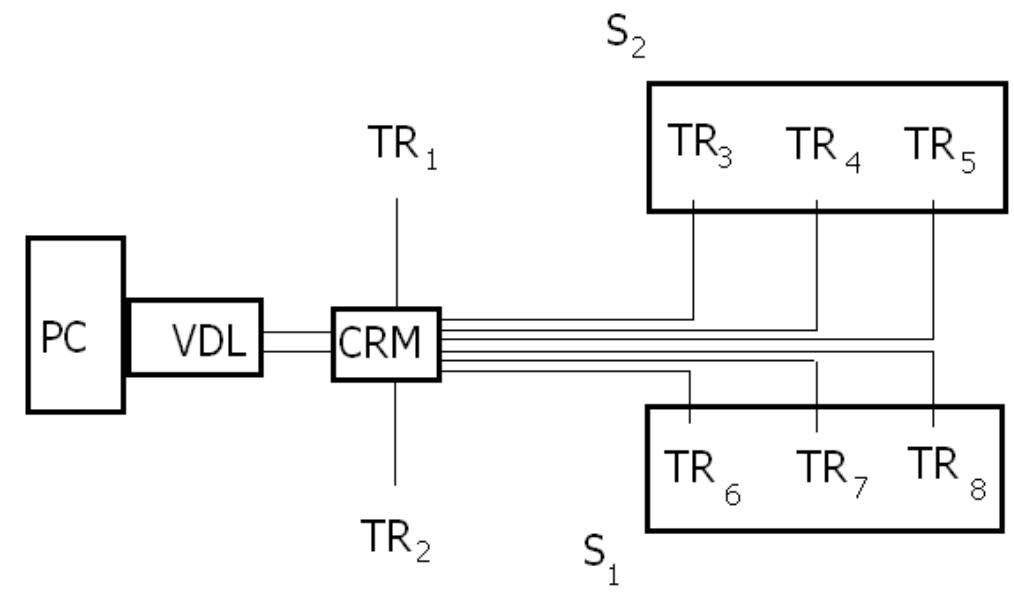

Figure 3: Block diagram of set-up experiment (PC - computer, VDL - Virtual Data Logger, CRM - Channel Relay Multiplexer, S - specimen, TR - Thermal Resistor)

(Bilek at all, 2007))

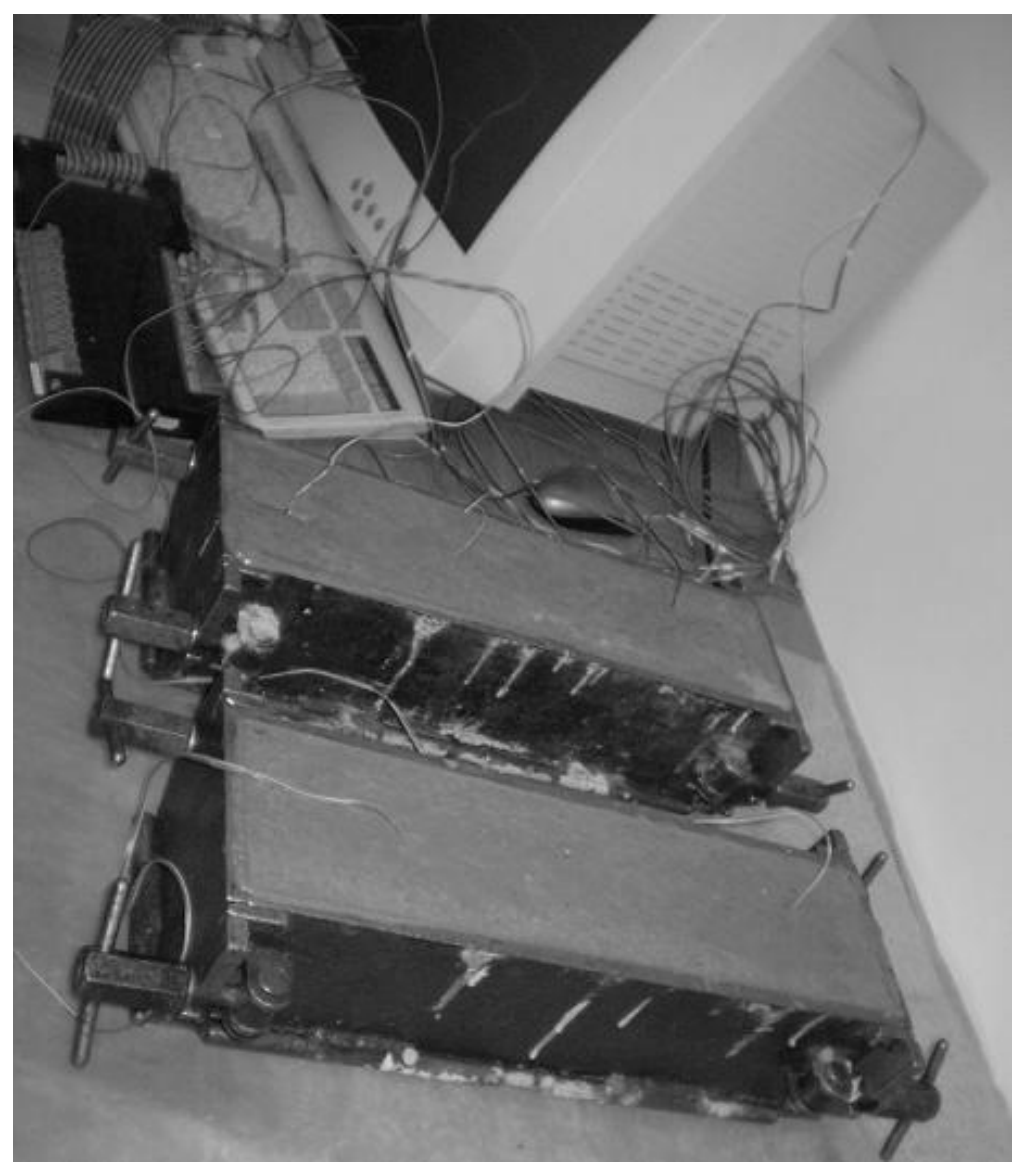

Figure 4: Experimental set-up of measuring 


\section{DISCUSSION}

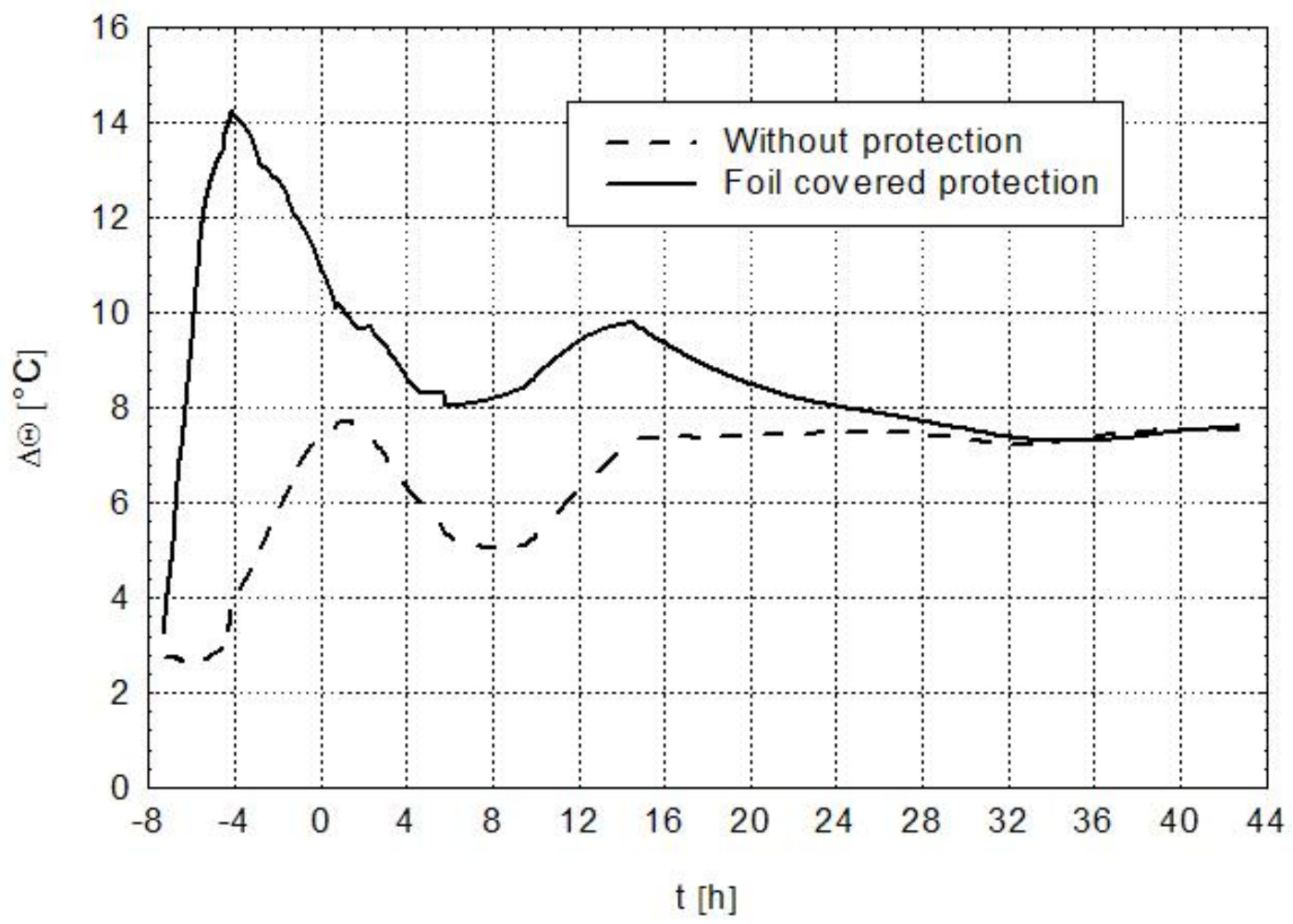

Figure 5: Temperature history

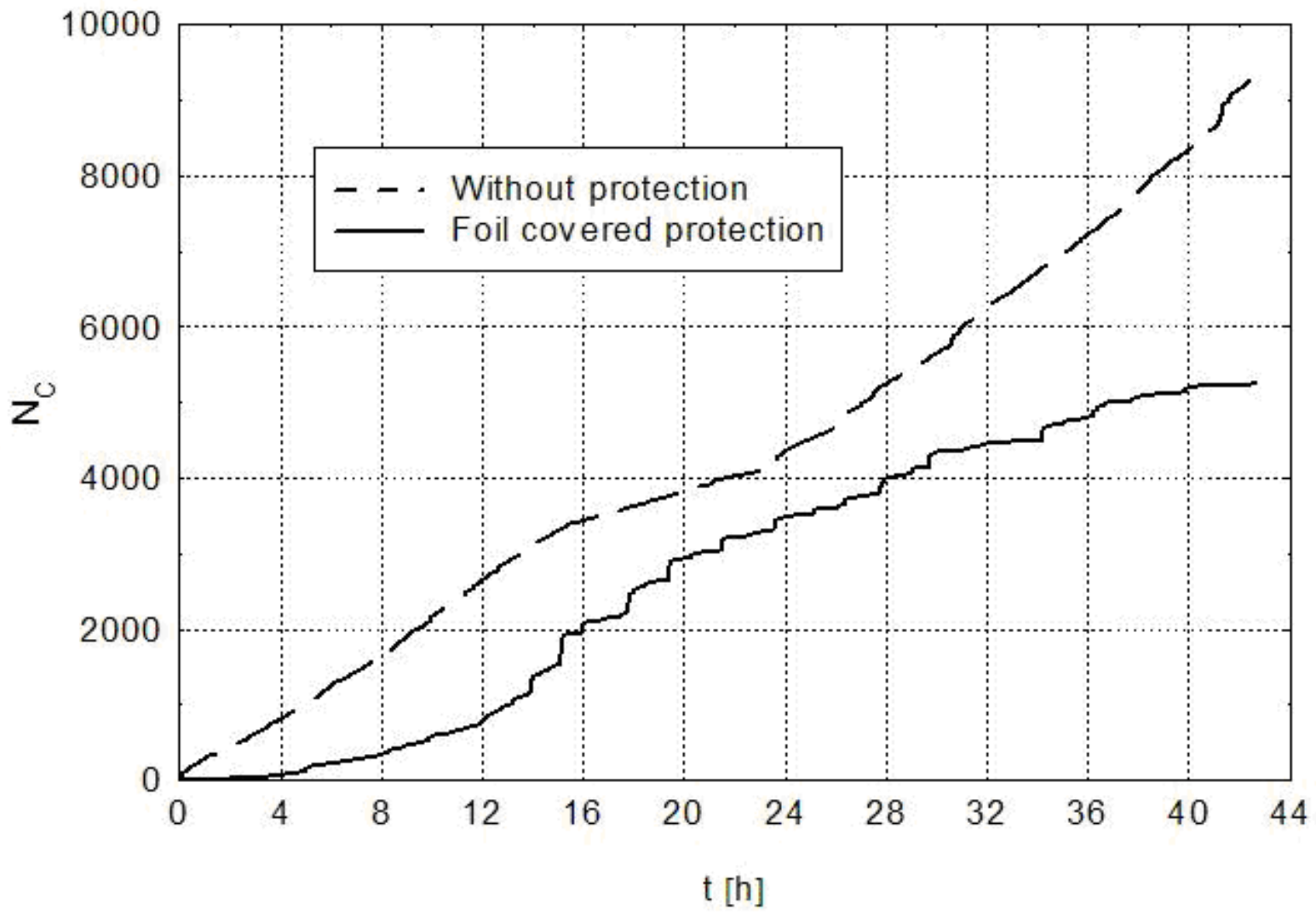

Figure 6: Accumulating the counts from all the detected emissions 
Temperature history of observed specimens is of interest for up to a day. One sample was sealed by PE foil to avoid any water exchange with the environment; the beam was cured without any water exchange prevention. (Mazal P. et all, 2007)

For acoustic emissions, the defect produces its own signal as it grows, and this signal is detected by a remote sensor. This is fundamentally different from most non-destructive methods, so the acoustic emission has a unique set of capabilities and limitations. Properly used in suitable combinations with other methods, the acoustic emission brings major cost savings and added effectiveness to durability.

\section{CONCLUSION}

Volume variations of concrete structures are connected with autogenous shrinkage and changes in humidity. The interesting part of concrete setting is temperature observation with a dependence on time. The application of the acoustic emission method to determine cracks in structures is the next step of this experiment.

A new technique of recorded signal analysis has also been applied. (Smutny J. et. all., 2001).

In future, some interesting methods to describe the hardening processes such as impedance spectroscopy, impact echo, non-linear ultrasonic spectroscopy etc. as well as non-traditional analysis will be applied. (Korenska M. et. all., 2001,2008; Ficker T., 2008; Pazdera L. et all, 2007)

\section{ACKNOWLEDGEMENT}

This research has been supported by the research project MSM 0021630519 CIDEAS reg. No. 1M0579 and GACR 103/07/0183

\section{REFERENCES}

Aitcin, P.C., (1998), High Performance Concrete, E\&FN Spon, London, 1998, 683 p.

Bilek, V.; Pazdera, L.; Topolář, L. (2007) Studium vývoje mikrotrhlin během tuhnutí a zrání betonu prostřednictvím akustické emise, in: 6. Konference Technologie betonu, Technologie, Provádění a kontrola betonových konstrukcí, 11. 4. 2007, ed. by Pardubice: CBS, s. 72-76, ISBN: 978-80-903807-4-5 (only in Czech language).

Bilek V, Mosler T et al. (2001), Development of fracture characteristics of cement pastes and causes of microcracking Conference Information: 4th International Conference on Fracture Mechanics of Concrete Structures, Cachan, France Fracture Mechanics Of Concrete Structures, Vols 1 And 2 Pages: 177-181, Published: 2001.

Ficker T., (2008) Fractal Strength of Cement Gels and Universal Dimension of Fracture Surfaces, Theoretical and applied fracture mechanics, Vol. 50, Iss. 2, pp. 167-171.

Korenska M, Manychova M, (2008) Nonlinear Ultrasonic Spectroscopy used to Detection of Ceramic Structure Damage, Nonlinear Acoustics Fundamentals and Applications, AIP conference proceedings, Vol. 1022, pp. 541-544. 
Korenska M, Pazdera L, Ritickova L, (2001), Study of correlation between acoustic emission and damaging of reinforced concrete, 6th International Conference of the Slovenian Society for Non Destructive Testing, Portoroz, slovenia, pp.181-184.

Mazal P, Pazdera L, Kolar L. (2005), Advanced acoustic emission signal treatment in the area of mechanical cyclic loading, 8th International Conference of the Slovenian Society for Non-Destructive Testing, Conference Proceedings - Application of Contemporary Non-Destructive Testing in Engineering, pp. 283-292, 2005.

Mazal P., Pazdera L., Fiala J. (2007) Contribution to Identification of Cyclic Damage Development of AlMg Alloy, European NDT Days in Prague 2007, NDE for Safety, International Conference, Prague, pp. 169-174.

Morin, R., Haddad, G. and Aïtcin, P.C.: (2002), Crack-Free High Performance Concrete Structures, Concrete International, V.24, No.9, Sep.2002, pp. 43-48.

Pazdera L, Smutny J, Janostik D, Korenska M, Prouzova P, (2007), Study of metal timber join by acoustic emission method, 8th International Conference of the Slovenian Society for Non-Destructive Testing, Conference Proceedings - Application Of Contemporary Non-Destructive Testing In Engineering, pp. 299-307.

Pollock, A. A., (1988), Practical guide to acoustic emission testing, Physical Acoustic Corporation, Princeton, New Jersey, USA.

Smutny J, Pazdera L., (2004) New techniques in analysis of dynamic parameters of rail fastening, INSIGHT, Vol, 46 Iss, 10, pp. 612-615, 2004. 